\title{
Types of chronic conditions combinations and initial cancer treatment among elderly Medicare beneficiaries with localised prostate cancer
}

\author{
A. D. Raval ${ }^{1,2,3}$, S. Madhavan ${ }^{3}$, M. D. Mattes ${ }^{4}$, and U. Sambamoorthi ${ }^{3}$ \\ ${ }^{1}$ Healthcore Inc., Wilmington, DE, USA \\ ${ }^{2}$ Department of Urology, School of Medicine, West Virginia University, Morgantown, WV, USA \\ ${ }^{3}$ Department of Pharmaceutical Systems and Policy, School of Pharmacy, West Virginia \\ University, Morgantown, WV, USA \\ ${ }^{4}$ Department of Radiation Oncology, School of Medicine, West Virginia University, Morgantown, \\ WV, USA
}

\section{Abstract}

Objective-To examine the association between types of chronic conditions combinations and initial cancer treatment among elderly Medicare beneficiaries with localised prostate cancer.

Methods-A population-based retrospective cohort study was conducted using the Surveillance, Epidemiology and End Results (SEER)-Medicare linked database. The study cohort consisted of elderly men ( $\geq 66$ years) with localised prostate cancer diagnosed between 2002 and $2009(N=98,264)$. The initial cancer treatment received during the 6 months after cancer diagnosis consisted of (i) radical prostatectomy (RP); (ii) radiation therapy (RT); (iii) hormone therapy; and (iv) no treatment. Pre-existing chronic conditions were classified into the following eight groups: (i) only cardiometabolic conditions (CM); (ii) only mental health conditions (MH); (iii) only respiratory conditions (RESP); (iv) CM and MH; (v) CM and RESP; (vi) MH and RESP; (vii) all three conditions, CM, MH and RESP; and (viii) none of the three types of conditions.

Results-Only 20\% did not receive any cancer treatment; $47.4 \%, 22.1 \%$ and $10.5 \%$ received RT, RP, and hormone therapy, respectively. In multinomial logistic regression, elderly men with only RESP were more likely to receive RP as compared with those with all the three types of chronic conditions; those with only CM, only RESP, CM and MH or CM and RESP were more likely to receive RT. No significant associations were observed between the receipt of hormone therapy and types of chronic conditions.

Conclusions-A significant proportion of elderly men with chronic conditions have received aggressive initial cancer treatment. Our study findings suggest a conservative approach for the

Correspondence to: Amit Raval, Healthcore, Inc., 123 Justison Street, Suite 200, Wilmington-DE 19801-5134, USA, Tel.: 302-230-2020, Fax: 302-230-2198, amitraval.heor.wvu@ gmail.com. 
initial prostate cancer treatment among elderly men with significant chronic conditions and localised prostate cancer.

\section{Introduction}

Chronic conditions are common among elderly men diagnosed with prostate cancer in the United States. Every 3 in 10 elderly men with incident prostate cancer have at least one preexisting chronic condition out of 16 chronic conditions included in the Charlson Comorbidity Index (CCI) (1). As elderly men with prostate cancer are at greater risk for mortality because of non-cancer conditions as compared with risk for mortality because of cancer, the practitioners determine the course of cancer treatment after taking into account the presence of pre-existing chronic conditions in addition to stage at cancer diagnosis and life expectancy. The clinical practice guidelines of the American Urology Association (2) and the National Cancer Comprehensive Network (3) recommend against the use of aggressive treatment such as radical prostatectomy (RP) or radiation therapy (RT) among men who have significant chronic conditions due to limited benefits and risk of adverse events due to RP or RT.

The presence of pre-existing chronic conditions influences the receipt of the initial cancer treatment (4-8) in elderly men with prostate cancer. Prior studies have used the CCI score to summarise the impact of chronic conditions on cancer treatment. These studies have reported varying associations between the presence of chronic conditions and cancer treatment. Two retrospective studies reported that men with prostate cancer and greater CCI scores were less likely to receive the RP/RT as compared with those with lower CCI scores $(6,9)$. Conversely, two studies reported that men with prostate cancer and greater CCI scores were more likely to receive the RP/RT as compared with those with lower CCI scores $(7,8)$. Weighted summary scores such as CCI may not be useful in determining the course of prostate cancer treatment. Therefore, it is important to analyse the relationship between types of chronic conditions combinations and treatment for prostate cancer.

Elderly men with prostate cancer suffer from different types of chronic conditions. For example, cardiometabolic (CM) conditions (18.1\%), chronic obstructive pulmonary disease (COPD) (9.8\%), (1) and depression (9\%) were reported to be highly prevalent among elderly men with prostate cancer (10). Among elderly men with prostate cancer, choice of cancer treatment can be affected by the types of chronic conditions combinations. Two previous studies have examined the association between specific chronic conditions and treatment for prostate cancer. Hall et al. found that men with congestive heart failure were less likely to receive surgical therapy as compared with those without congestive heart failure (11). Using the SEER-Medicare linked data, Prasad et al. reported that men with depression were less likely to receive aggressive therapy such as RP or RT as compared with those without depression (12). These studies did not account for the presence of other pre-existing chronic conditions, which may influence the choice of cancer treatment.

To date, studies analysing the associations between types of chronic conditions and their combinations and receipt of initial treatment for prostate cancer are non-existent. We recognise that the knowledge gap in this area may be as a result of challenges in defining 
combinations of chronic conditions. If one were to capture the chronic conditions and their combinations using only the 16 chronic conditions captured by the CCI, one can expect 120 two-disease combinations, 560 three-disease combinations and 1820 four-disease combinations with more than 20 trillion combinations of chronic conditions overall. If one were to capture chronic conditions and their combinations using the Elixhauser Index (13), which consists of 30 conditions, or Piette et al.'s framework, which can consist of 53 chronic conditions (14), one can expect to have even more combinations. While it is possible to use computer software to easily capture all the combinations from data sets, such analyses may not provide any actionable intelligence.

Therefore, it is necessary to operationalise combinations of chronic conditions to a reasonable and manageable number of conditions that would help clinical management as well. This study is an attempt to define clinically meaningful combinations of chronic conditions based on a conceptual framework for research, policy, programme and practice (15), and use the combinations to examine the association between types of chronic conditions combinations and initial cancer treatment among elderly men with incident prostate cancer. As the presence of $\mathrm{CM}$ conditions, respiratory conditions and mental health conditions (> 5\% prevalence) are common as compared with all other types of chronic conditions ( $\leq 5 \%$ prevalence), we selected these conditions to identify the types of chronic conditions. Therefore, the primary objective of this study is to examine the associations between the types of pre-existing chronic conditions and initial cancer treatment among feefor-service Medicare beneficiaries with incident prostate cancer. We hypothesised that elderly men with localised prostate cancer with all three types of chronic conditions will be less likely to be treated with RP or RT as those are at high risk of death because of noncancer conditions; however, as compared with those with all three types of chronic conditions, those with particular types of chronic conditions will be more likely to be treated with RP or RT.

\section{Method}

\section{Study design}

This study adopted a retrospective cohort design with a baseline and follow-up period. The date of diagnosis of prostate cancer was considered as the index date. The baseline period was defined as 1 year before the index date. The types of chronic conditions combinations and all other independent variables were identified during the baseline period. The follow-up period consisted of 6 months after prostate cancer diagnosis. Initial prostate cancer treatment was measured during this period as depicted in the Figure 1.

\section{Data sources}

This study utilised the SEER-Medicare linked data-base for the years 2001-2010.

The SEER data are the high-quality population-based cancer registries data on cancer incidence and their treatment and outcomes. At present, it comprised 18 population-based cancer registries covering $24 \%$ of US population (16). The National Cancer Institute provides the cases of cancers in a customised file, the Patient Entitlement and Diagnosis 
Summary File (PEDSF). Almost every (98\%) cases of cancers are ascertained from the medical records and $93 \%$ of cases were linked with Medicare insurance claims $(17,18)$. This study was approved under expedited category by the Institutional Review Board of the West Virginia University.

\section{Study cohort}

The study cohort was based on 358,439 men with an incident diagnosis of prostate cancer. Elderly men with multiple cancers $(\mathrm{N}=65,794)$, diagnosed with prostate cancer at the time of autopsy or on the death certificate $(N=2944)$, younger than 66 years of age $(N=97,159)$, died during the observation period $(N=41,205)$, did not have continuous fee-for-service enrolment in Medicare Part A and B during the observation period $(N=70,559)$ and missing information on cancer stage at diagnosis, race, income, education or county of residence ( $N$ $=5390)$ were excluded. We restricted our study population to those localised prostate cancer ( $\leq \mathrm{T} 2$ ) with non-metastatic (M0), non-node positive cancer (N0) and having no spread to nearby organ or tissue ( $\geq \mathrm{T} 3$ ). We also excluded men who were diagnosed with advanced prostate cancer $(N=5556)$. Thus, the final cohort consisted of 98,264 elderly men with incident prostate cancer. Figure 2 summarises the study cohort selection process.

\section{Dependent variable}

Initial cancer treatment-The receipt of initial prostate cancer treatment as either receipt of radiation or surgical therapy or hormonal therapy was identified using inpatient, outpatient and carrier files with appropriate International Classification of Diseases, Ninth Revision, Clinical Modification (ICD-9-CM) diagnostic and procedure codes, Current Procedural Terminology (CPT) or Healthcare Common Procedure Coding System (HCPCS) codes or revenue centre codes during the 6 months after the index date $(19,20,21)$. Appendix 1 comprises the details of the codes used to identify the initial cancer treatment in the current study.

We classified elderly men with the initial cancer treatment receipt into four groups following a hierarchy: (i) those who received RP alone or along with any RT or hormone therapy; (ii) those who received RT alone or along with hormone therapy; (iii) those who only received hormone therapy; and (iii) no-treatment group as those who did not receive RP or RT or hormone therapy during 6 months after the diagnosis of prostate cancer. Such grouping of the initial cancer treatment is the hierarchical preference for particular cancer treatments among men with prostate cancer.

\section{Key independent variable}

Types of pre-existing chronic conditions-Chronic conditions were identified using one inpatient or two outpatient claims with ICD-9-CM diagnostic codes and procedure codes during the year before diagnosis of prostate cancer (Appendix 2). To define clinically meaningful combinations of chronic conditions, we used several criteria. These included high prevalence, specific organ domains, common pathophysiology and synergistic management of different chronic conditions (22). Based on prior literature, conceptual model of chronic condition measurement that is imperative for research, policy, programme and practice and clinician input, we selected 12 chronic conditions. These 12 chronic 
conditions were among the 20 conditions selected by the US Department of Health and Human Services for research, policy, programme and practice (15). These 12 conditions were grouped into three broad categories using specific organ domains, common pathophysiology and synergistic management. They were CM conditions (diabetes, coronary artery disease, congestive heart failure and cardiac arrhythmia), mental health conditions (anxiety, bipolar disorders, depression, schizophrenia, post-traumatic stress disorders and psychosis) and respiratory conditions (COPD and asthma). Such types of classifications have been used in many studies (23-25). Furthermore, we classified these three types of chronic conditions combinations into eight mutual categories: (i) CM conditions only; (ii) mental health conditions only; (iii) respiratory conditions only; (iv) $\mathrm{CM}$ and mental health conditions; (v) CM and respiratory conditions; (vi) mental health and respiratory conditions; (vii) all three conditions - CM, mental health and respiratory conditions; and (viii) none of the three types of conditions.

\section{Other independent variables}

The current study adapted a framework of the expanded behavioural model for the use of health services widely known as the Andersen Behavioral Model (26). According to this model, initial cancer treatment is influenced by predisposing, enabling, need and external environmental factors.

Predisposing characteristics-The demographic factors, such as age, race/ethnicity and marital status, were included as the predisposing characteristics. Age at the time of diagnosis was identified from the PEDSF file and was categorised into two groups (66-74 years and 75 and above years). Based on age at the time of diagnosis, the life expectancy was calculated using the life table for men derived from the Social Security Administration tables (27) and the life-expectancy categories were dichotomised to (i) $\leq 10$ years and (ii) > 10 years at the time of diagnosis of prostate cancer to have a compliance with stated guideline recommendations (3). Race/ethnicity and marital status were also derived from the PEDSF file. Race/ethnicity was categorised into four groups: White, African American, Hispanic and other. Marital status was derived from the PEDSF file and categorised into four groups: married, divorced/separated, unmarried and others.

Enabling characteristics-Enabling factors were census tract level median income, census tract level median education and visit to primary care centre. The PEDSF file contains census tract level information on income and education variables. The visits to a primary care provider were identified during the baseline period. HCPCS codes of 84152, 84154, 84153, G0103 represented prostate-specific antigen test, and these codes were used to identify prostate cancer screening during the baseline period.

Need characteristics-We utilised the American Joint Committee on Cancer tumournode metastases classifications for staging of prostate cancer. We classified the localised stage of cancer into two categories: (i) T1 and (ii) T2 (2).

During the baseline period, a very small percentage of men $(<5 \%)$ had at least one of the other 42 conditions, which were not captured by the $\mathrm{CM}$, mental health and respiratory 
conditions. These 42 other conditions were derived using the list of chronic conditions from published literature (14). The total number of other chronic conditions were calculated and categorised into two groups as the presence of either ' $0-1$ condition' or ' 2 or more conditions'.

External environmental characteristics-External environmental characteristics comprised individual's resident-level county, region, county-level radiation oncology units and urology units. The 18 regions of SEER were categorised into four groups: (i) northeast; (ii) south; (iii) north-central; and (iv) west based on the list provided by NCI (28).

The Area Health Resource files (AHRF) were used to derive county-level health care resources (28) especially the number of radiation oncology units, and urology units in counties. SEER-Medicare files were matched with the AHRF using Federal Information Processing Standards state and county codes (28). For the purposes of our analyses, the quartiles of radiation oncology units and urology units at the county level were calculated.

In addition, the year of diagnosis was also considered as an independent factor.

\section{Statistical analyses}

The significant differences in predisposing, enabling, need and external environmental characteristics by types of pre-existing chronic conditions among the men with incident prostate cancer were tested using $\chi^{2}$ tests. Multinomial logistic regressions were performed to test the association between types of chronic conditions combinations and cancer treatment receipt (RP, RT, hormone therapy only) after controlling predisposing, enabling, need and external environmental characteristics. In this regression, cancer stage was additionally included as a need factor. As the cancer stage and life expectancy are key determinants of the cancer treatment receipt for elderly men with prostate cancer, four subgroups were created as follows: (i) cancer stage $\leq \mathrm{T} 1$ and life expectancy $\leq 10$ years; (ii) cancer stage $\leq \mathrm{T} 1$ and life expectancy $>10$ years; (iii) cancer stage $\geq \mathrm{T} 2$ and life expectancy $\leq 10$ years; and (iv) cancer stage $\geq \mathrm{T} 2$ and life expectancy $>10$ years. Separate multivariable multinomial logistic regressions were carried out to examine the association between types of chronic conditions combinations and cancer treatment for each of the four subgroups. All statistical analyses were carried out using Statistical Analysis System (SAS) version 9.4 (SAS Institute Inc., Cary, NC).

\section{Results}

\section{Study population}

Table 1 summarises the characteristics of the study cohort $(N=98,246)$. A majority of men were diagnosed with prostate cancer between ages 66 and 74 years (59.7\%). The study cohort was primarily White $(81.8 \%)$ and married $(67.1 \%)$. Nearly three-quarters of men had a primary care visit $(73.7 \%)$. 


\section{Study population by types of chronic conditions combinations}

Table 2 reports the characteristics of the study population by types of chronic conditions combinations. Overall, $54 \%$ of the study population had either CM, mental health or respiratory conditions during the year before prostate cancer diagnosis and $46 \%$ had none of these conditions. The majority of men had only CM conditions (35.5\%), followed by men with both $\mathrm{CM}$ and respiratory conditions (8\%), only respiratory conditions (5.2\%), CM and mental health conditions ( $2.1 \%)$, only mental health conditions (1.9\%) and mental health conditions and respiratory conditions $(0.4 \%)$. Significant differences in the predisposing, enabling, need and external environmental factors by types of chronic conditions combinations were observed among elderly men with incident prostate cancer.

\section{Types of chronic conditions combinations and initial cancer treatment type}

Table 3 displays the rates of initial cancer treatment by types of chronic conditions combinations. Overall, $80.3 \%$ of the study population received either RP/RT or hormone therapy during 6-month after cancer diagnosis: $22.1 \%$ received RP, $47.4 \%$ received RT, $10.5 \%$ received hormone therapy and $20 \%$ received no treatment for cancer. The highest rate of RP was observed among those with only mental health conditions (24.5\%), whereas the highest rate of RT was observed among elderly men with only CM conditions (49.5\%). The highest rates of only hormone therapy $(15.7 \%)$ or no treatment $(24.7 \%)$ were observed among elderly men with prostate cancer with all the three types of chronic conditions $(59.4 \%)$.

The bottom panel of Table 3 displays the AORs and 95\% CIs from the multinomial logistic regression on initial cancer treatment categories. After adjusting for predisposing, enabling, need factors including cancer stage and external environmental factors, elderly men with none of three types of chronic conditions ( $\mathrm{AOR}=1.31,95 \% \mathrm{CI}$ : $1.06-1.62)$ or only respiratory conditions ( $\mathrm{AOR}=0.30 ; 95 \% \mathrm{CI}$ : $1.04-1.62$ ) were more likely to receive $\mathrm{RP}$ as compared with those with all the three types of chronic conditions. These groups were also more likely to receive RT. Additionally, elderly men with only $\mathrm{CM}$ conditions ( $\mathrm{AOR}=1.61$, 95\% CI: 1.35-1.93), both CM and mental health conditions (AOR $=1.26$ 95\% CI: 1.02 1.56 ) or respiratory conditions ( $\mathrm{AOR}=1.47,95 \% \mathrm{CI}$ : $1.22-1.77$ ) were more likely to receive RT. Those with only mental health conditions were as likely as those with all the three types of chronic conditions to receive initial cancer treatment. There were no statistically significant relationships between types of chronic conditions and receipt of only hormone therapy among elderly men with prostate cancer.

\section{Subgroup analyses}

Table 4 describes the percentage of those received the treatment, AOR with their 95\% CI for the receipt of initial cancer treatment for each subgroup. Among elderly men with cancer stage $\mathrm{T} 1$ or $\mathrm{T} 2$ and life expectancy at diagnosis $>10$ years, those with only respiratory conditions were more likely to receive the RP or RT; those with only CM conditions and CM and respiratory conditions were more likely to receive RT as compared with those with all three types of chronic conditions. However, among those with cancer stage T1 and life expectancy at diagnosis $\leq 10$ years, expect those with $\mathrm{CM}$ and mental health conditions, all other groups were less likely to receive RP as compared with those with all the three types of 
chronic conditions and no significant differences in the RP by types of chronic conditions combinations were observed in these subgroups. In addition, no significant differences in the types of chronic conditions combinations and hormone therapy receipt were found in four subgroups.

\section{Discussion}

The current study aimed to examine the association between types of chronic conditions combinations and receipt of initial cancer treatment using the largest population-based registry data of the United States. We found that nearly three in four elderly men with incident prostate cancer received initial cancer treatment. Our findings are consistent with published studies $(4,11)$. Elderly men with none of the three types of chronic conditions were more likely to receive initial cancer treatment compared with those with all the three types of chronic conditions. Clinical guidelines encourage initial cancer treatment with RP or RT for men without pre-existing chronic conditions because these men are considered relatively healthy and therefore may have longterm survival benefit and a better prognosis from initial cancer treatment.

Despite the availability of accurate estimates of survival based on age, CCI score and cancer stage $(4,5,7)$, elderly men with prostate cancer and some types of chronic conditions combinations were more likely to be treated for cancer as compared with those with all the three types of chronic conditions. These findings suggest that many elderly men with chronic conditions may have been treated aggressively even though such treatments may not provide long-term survival benefit (29) and may lead to adverse health consequences (30). The current guidelines for prostate cancer treatment recommend 'no aggressive treatment should be an option for those with serious chronic conditions'. However, these guidelines did not explicitly define the term 'serious chronic conditions'. Therefore, the providers may not consider the presence of some types of chronic conditions serious enough and may have treated the cancer aggressively with RP/RT. Our study reinforces the need for clinical guidelines that explicitly incorporate the types of chronic conditions combinations along with age and life expectancy to recommend cancer treatment options for elderly men with prostate cancer.

Even after controlling for cancer stage and other factors, men with prostate cancer and only respiratory conditions were more likely to receive RP and those with only CM conditions were more likely to receive RT as the initial cancer treatment as compared with those with all the three types of chronic conditions. Prior research has shown that elderly men with CM conditions may not benefit from cancer treatment as these men are at high risk for noncancer-related mortality $(4,29)$. There is also evidence of the increased risk for adverse clinical outcomes such as poor wound healing, risk of peri-operative complications resulting from cancer treatment $(31,32)$ and treatment regret $(30)$ among elderly men with prostate cancer and pre-existing CM conditions. Our study findings highlight the need to increase the physician and patient awareness of adverse risks associated with active treatment among elderly men with prostate cancer and CM conditions. 
Another noteworthy finding from this study is that the elderly men with prostate cancer and only mental health conditions and both mental health conditions and respiratory conditions did not have significant difference between the receipt of RP/RT treatment. This finding is not consistent with a published study in which elderly men with prostate cancer and mental health conditions were less likely to receive aggressive treatment compared with elderly men without mental health conditions. The difference in findings could be explained by lack of adjustments for types of chronic conditions combinations (12).

Closer examination of our study findings in the subgroup analyses, the relationship between types of chronic conditions combinations and the receipt of initial cancer varied by cancer stage and life expectancy at diagnosis. Among those with significant less life expectancies ( $\leq$ 10 years) having T1 stage, except those with CM conditions and mental health conditions, and those with all the chronic conditions categories were less likely to receive the RP and no significant differences were observed in the receipt of RT by types of chronic conditions combinations. These findings suggested the consistencies with the literature that those with less life expectancy should not be treated aggressively. However, those with cancer stage T1 and having life expectancy more than 10 years, some types of chronic conditions combinations were associated with greater use of RP or RT. The use of such aggressive treatment is a matter of debate because no clear benefits are associated with RP or RT in these particular subgroups.

To interpret the study findings in context, we point out the strengths and limitations of the current study. Our study is timely and is aligned with the goals of the Office of Cancer Survivorship and Institute of Medicine regarding the management of prostate cancer in the presence of pre-existing chronic conditions. To the best of our knowledge, our study is the largest population-based registry study to assess the association between the types of chronic conditions combinations and initial cancer treatment among elderly men with prostate cancer.

As the current study used observational data, the causal associations between the presence of types of chronic condition combinations and initial cancer treatment could not be determined. Our study population was restricted to men older than 66 years and older. Therefore, the findings cannot be generalisable to younger men with prostate cancer. In addition, as the presence of chronic conditions were identified using validated codes from the literature, the clinical severity and seriousness of chronic conditions could not be measured, which would also be important factor for the initial cancer treatment receipt and outcomes among men with prostate cancer. To over-come this issue to some extent, we also utilised the number of primary care visits or emergency visits as controlled variables for serve as a proxy for severity of disease. However, we did not observe any significant difference in receipt of cancer treatment even after adjusting for such controlled variables.

\section{Conclusion}

Elderly men with prostate cancer and all chronic condition categories (except for only mental health conditions and both mental health and respiratory conditions) were more likely to receive initial cancer treatment with either RP or RT as compared with all the three 
types of chronic conditions. Although there is no evidence that RP or RT can be beneficial in long-term for elderly men with prostate cancer and pre-existing chronic conditions, an overwhelming majority of men with chronic conditions received cancer treatment.

\title{
Acknowledgments
}

\author{
Funding \\ This project was supported by the Agency for Healthcare Research and Quality (AHRQ) Grant R24HS018622-03 \\ and National Institute of General Medicine Sciences Grant U54GM104942. The content is solely the responsibility \\ of the authors and does not necessarily represent the official views of AHRQ and NIH.
}

\section{References}

1. Edwards BK, Noone AM, Mariotto AB, et al. Annual report to the nation on the status of cancer, 1975-2010, featuring prevalence of comorbidity and impact on survival among persons with lung, colorectal, breast, or prostate cancer. Cancer. 2014; 120(9):1290-314. [PubMed: 24343171]

2. Thompson I, Thrasher JB, Aus G, et al. Guideline for the management of clinically localized prostate cancer: 2007 update. J Urol. 2007; 177(6):2106-31. [PubMed: 17509297]

3. Mohler J, Bahnson RR, Boston B, et al. NCCN clinical practice guidelines in oncology: prostate cancer. J Natl Compr Canc Netw. 2010; 8(2):162-200. [PubMed: 20141676]

4. Albertsen PC, Moore DF, Shih W, Lin Y, Li H, Lu-Yao GL. Impact of comorbidity on survival among men with localized prostate cancer. J Clin Oncol. 2011; 29(10):1335-41. [PubMed: 21357791]

5. Daskivich TJ, Fan KH, Koyama T, et al. Effect of age, tumor risk, and comorbidity on competing risks for survival in a U.S. population-based cohort of men with prostate cancer. Ann Intern Med. 2013; 158(10):709-17. [PubMed: 23689764]

6. Schymura MJ, Kahn AR, German RR, et al. Factors associated with initial treatment and survival for clinically localized prostate cancer: results from the CDC-NPCR Patterns of Care Study (PoC1). BMC Cancer. 2010; 10:152. 2407-10-152. [PubMed: 20403178]

7. Daskivich TJ, Chamie K, Kwan L, et al. Overtreatment of men with low-risk prostate cancer and significant comorbidity. Cancer. 2011; 117(10):2058-66. [PubMed: 21523717]

8. Daskivich TJ, Lai J, Dick AW, et al. Variation in treatment associated with life expectancy in a population-based cohort of men with early-stage prostate cancer. Cancer. 2014; 120(23):3642-50. [PubMed: 25042117]

9. Desch CE, Penberthy L, Newschaffer CJ, et al. Factors that determine the treatment for local and regional prostate cancer. Med Care. 1996; 34(2):152-62. [PubMed: 8632689]

10. Jayadevappa R, Malkowicz SB, Chhatre S, Johnson JC, Gallo JJ. The burden of depression in prostate cancer. Psychooncology. 2012; 21(12):1338-45. [PubMed: 21837637]

11. Hall HI, Satariano WA, Thompson T, Ragland KE, van den Eeden SK, Selvin S. Initial treatment for prostate carcinoma in relation to comorbidity and symptoms. Cancer. 2002; 95(11):2308-15. [PubMed: 12436436]

12. Prasad SM, Eggener SE, Lipsitz SR, Irwin MR, Ganz PA, Hu JC. Effect of depression on diagnosis, treatment, and mortality of men with clinically localized prostate cancer. J Clin Oncol. 2014; 32(23):2471-8. [PubMed: 25002728]

13. Elixhauser A, Steiner C, Harris DR, Coffey RM. Comorbidity measures for use with administrative data. Med Care. 1998; 36(1):8-27. [PubMed: 9431328]

14. Piette JD, Kerr EA. The impact of comorbid chronic conditions on diabetes care. Diabetes Care. 2006; 29(3):725-31. [PubMed: 16505540]

15. Goodman RA, Posner SF, Huang ES, Parekh AK, Koh HK. Defining and measuring chronic conditions: imperatives for research, policy, program, and practice. Prev Chronic Dis. 2013; 25(10):E66. [PubMed: 23618546]

16. SEER*Stat Database: incidence-SEER 18 Regs Public Use, Nov. 2012 Sub (2000-2010)-linked to county attributes-total US, 1969-2011 counties. National Cancer Institute, Division of Cancer 
Control and Population Sciences, Surveillance Research Program, Cancer Statistics Branch; Bethesda, MD: 2013. Surveillance, Epidemiology, and End Results (SEER) Program.

17. SEER-Medicare: how the SEER \& Medicare data are linked? [Internet]. 2013. http:// appliedresearch.-cancer.gov/seermedicare/aboutdata/

18. Warren JL, Klabunde CN, Schrag D, Bach PB, Riley GF. Overview of the SEER-Medicare data: content, research applications, and generalizability to the United States elderly population. Med Care. 2002; 40(8 Suppl. IV):3-18.

19. Trantham LC, Nielsen ME, Mobley LR, Wheeler SB, Carpenter WR, Biddle AK. Use of prostatespecific antigen testing as a disease surveillance tool following radical prostatectomy. Cancer. 2013; 119(19):3523-30. [PubMed: 23893821]

20. Wong YN, Mitra N, Hudes G, et al. Survival associated with treatment vs observation of localized prostate cancer in elderly men. JAMA. 2006; 296(22):2683-93. [PubMed: 17164454]

21. Shahinian VB, Kuo YF, Freeman JL, Goodwin JS. Determinants of androgen deprivation therapy use for prostate cancer: role of the urologist. J Natl Cancer Inst. 2006; 98(12):839-45. [PubMed: 16788157]

22. Fortin M, Dubois MF, Hudon C, Soubhi H, Almirall J. Multimorbidity and quality of life: a closer look. Health Qual Life Outcomes. 2007; 6(5):52. [PubMed: 17683600]

23. Meraya AM, Raval AD, Sambamoorthi U. Chronic condition combinations and health care expenditures and out-of-pocket spending burden among adults, Medical Expenditure Panel Survey, 2009 and 2011. Prev Chronic Dis. 2015; 29(12):E12. [PubMed: 25633487]

24. Kadam UT, Uttley J, Jones PW, Iqbal Z. Chronic disease multimorbidity transitions across healthcare interfaces and associated costs: a clinical-linkage database study. BMJ Open. 2013; 10:120239.

25. Vyas A, Pan X, Sambamoorthi U. Chronic condition clusters and polypharmacy among adults. Int J Family Med. 2012; 2012:193168. [PubMed: 22900173]

26. Andersen RM. Revisiting the behavioral model and access to medical care: does it matter? J Health Soc Behav. 1995; 36(1):1-10. [PubMed: 7738325]

27. Actuarial life table [Internet]. 2014. http://www.ssa.gov/OACT/STATS/table 4c6.html.

28. Area resource file: overview [Internet]. 2014. http://ahrf.hrsa.gov/overview.htm.

29. Chamie K, Daskivich TJ, Kwan L, et al. Comorbidities, treatment and ensuing survival in men with prostate cancer. J Gen Intern Med. 2012; 27(5):492-9. [PubMed: 21935751]

30. Nguyen PL, Chen MH, Hoffman KE, et al. Cardiovascular comorbidity and treatment regret in men with recurrent prostate cancer. BJU Int. 2012; 110(2):201-5. [PubMed: 22085233]

31. Vavassori V, Fiorino C, Rancati T, et al. Predictors for rectal and intestinal acute toxicities during prostate cancer high-dose 3D-CRT: results of a prospective multicenter study. Int J Radiat Oncol Biol Phys. 2007; 67(5):1401-10. [PubMed: 17241754]

32. Tucker SL, Dong L, Bosch WR, et al. Late rectal toxicity on RTOG 94-06: analysis using a mixture Lyman model. Int J Radiat Oncol Biol Phys. 2010; 78(4):1253-60. [PubMed: 20598811] 
What's known

- $\quad$ Elderly men diagnosed with prostate cancer have greater risk of death resulting from non-cancer-related conditions. Therefore, cancer treatment decision should weigh the long-term benefits among those with significant chronic conditions. However, patterns of the initial cancer treatment among elderly men by different types of chronic conditions combinations have not been studied.

What's new

- $\quad$ Our study finds the significant use of active initial cancer treatment among men with low risk of dying due to prostate cancer.

- $\quad$ Our study highlights the need to improve initial cancer therapy among men with significant chronic conditions. 
Diagnosis of Prostate Cancer $2002-2009$

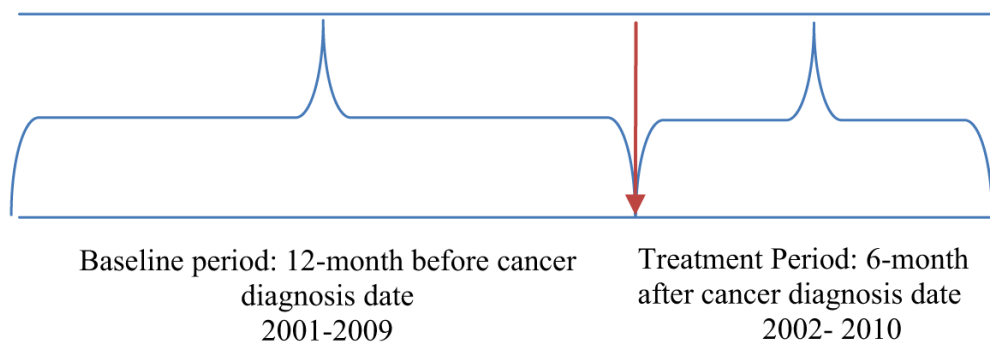

Figure 1.

Schematic presentation of the study design 


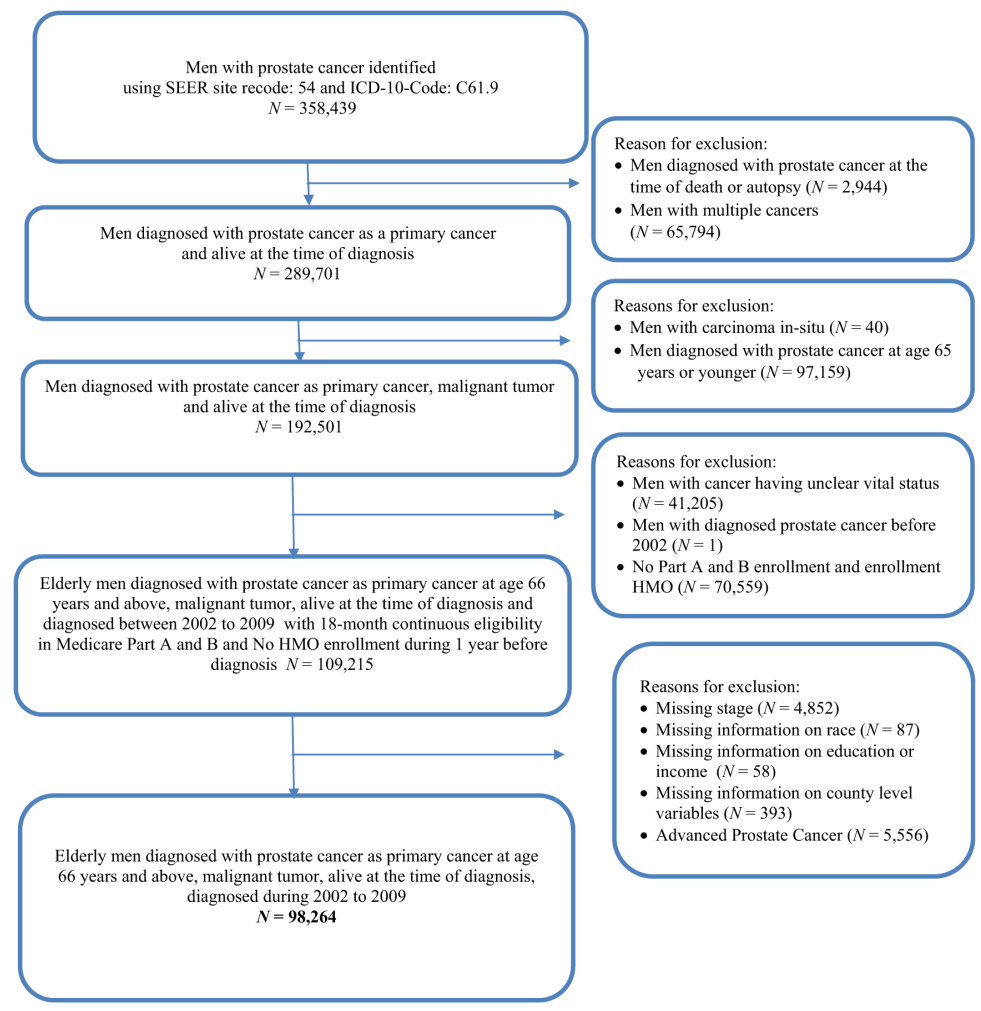

Figure 2.

Study cohort development flow diagram for study population of elderly Medicare beneficiaries diagnosed with localised prostate cancer 


\section{Table 1}

Characteristics of elderly Medicare beneficiaries with prostate cancer Surveillance, Epidemiology and End Results (SEER)-Medicare linked database 2002-2010

\begin{tabular}{|c|c|c|}
\hline & $N$ & $\%$ \\
\hline All & 98,264 & 100 \\
\hline \multicolumn{3}{|c|}{ Types of chronic conditions combinations } \\
\hline CM only & 34,916 & 35.5 \\
\hline MH only & 1838 & 1.9 \\
\hline RESP only & 5151 & 5.2 \\
\hline $\mathrm{CM}+\mathrm{MH}$ & 2086 & 2.1 \\
\hline $\mathrm{CM}+\mathrm{RESP}$ & 7783 & 7.9 \\
\hline $\mathrm{MH}+\mathrm{RESP}$ & 393 & 0.4 \\
\hline None & 45,209 & 46.0 \\
\hline All three & 888 & 0.9 \\
\hline \multicolumn{3}{|c|}{ Predisposing characteristics } \\
\hline \multicolumn{3}{|c|}{ Life expectancy at diagnosis } \\
\hline$\leq 10$ years & 14,941 & 15.2 \\
\hline$>10$ years & 83,323 & 84.8 \\
\hline \multicolumn{3}{|l|}{ Race/ethnicity } \\
\hline White & 80,339 & 81.8 \\
\hline African American & 11,021 & 11.2 \\
\hline Others & 6904 & 7.0 \\
\hline \multicolumn{3}{|l|}{ Marital status } \\
\hline Unmarried & 6483 & 6.6 \\
\hline Married & 65,957 & 67.1 \\
\hline Divorced/Separated & 12,574 & 12.8 \\
\hline Others & 13,250 & 13.5 \\
\hline \multicolumn{3}{|c|}{ Enabling characteristics } \\
\hline \multicolumn{3}{|c|}{ Quartile of median census 2000 income } \\
\hline$\$ 7-\$ 34,522$ & 24,428 & 24.9 \\
\hline$\$ 34,523-46,224$ & 24,493 & 24.9 \\
\hline$\$ 46,229-62,764$ & 24,569 & 25.0 \\
\hline$\$ 62,767-200,008$ & 24,774 & 25.2 \\
\hline \multicolumn{3}{|c|}{ Quartile of median census 2000 education } \\
\hline $0-8.52$ & 24,644 & 25.1 \\
\hline $8.53-15.16$ & 24,670 & 25.1 \\
\hline $15.17-26.09$ & 24,408 & 24.8 \\
\hline $26.1-100$ & 24,542 & 25.0 \\
\hline \multicolumn{3}{|l|}{ Visit to a PCP } \\
\hline Yes & 72,468 & 73.7 \\
\hline No & 25,796 & 26.3 \\
\hline
\end{tabular}




\begin{tabular}{|lll|}
\hline \multicolumn{2}{ll}{$N$} & $\%$ \\
\hline SEER regions & & \\
Northeast & 19,714 & 20.1 \\
South & 23,991 & 24.4 \\
North-Central & 12,236 & 12.5 \\
West & 42,323 & 43.1 \\
Quartile of radiation oncology & & \\
$0-1$ & 26,006 & 26.5 \\
2-6 & 21,990 & 22.4 \\
7-22 & 25,617 & 26.1 \\
23-147 & 24,651 & 25.1 \\
Quartile of urology centres & & \\
$0-3$ & 24,274 & 24.7 \\
$4-16$ & 24,018 & 24.4 \\
17-44 & 25,679 & 26.1 \\
$45-343$ & 24,293 & 24.7 \\
Year of diagnosis & & \\
$2002-2005$ & 50,817 & 51.7 \\
2006-2009 & 47,447 & 48.3 \\
Need characteristics & & \\
Number of chronic conditions & & \\
4 & 59,773 & 60.8 \\
$>1$ & 38,491 & 39.2 \\
T stage & & \\
T1 & 57,783 & 58.8 \\
T2 & 40,481 & 41.2 \\
\hline
\end{tabular}

Based on the data of 98,264 elderly men aged 66 years and older diagnosed with prostate cancer between 2002 and 2009 using a Surveillance, Epidemiology, and End Results (SEER)-Medicare linked data. CM, cardiometabolic conditions; MH, mental health conditions; PCP, primary care physician; RESP, respiratory conditions. 


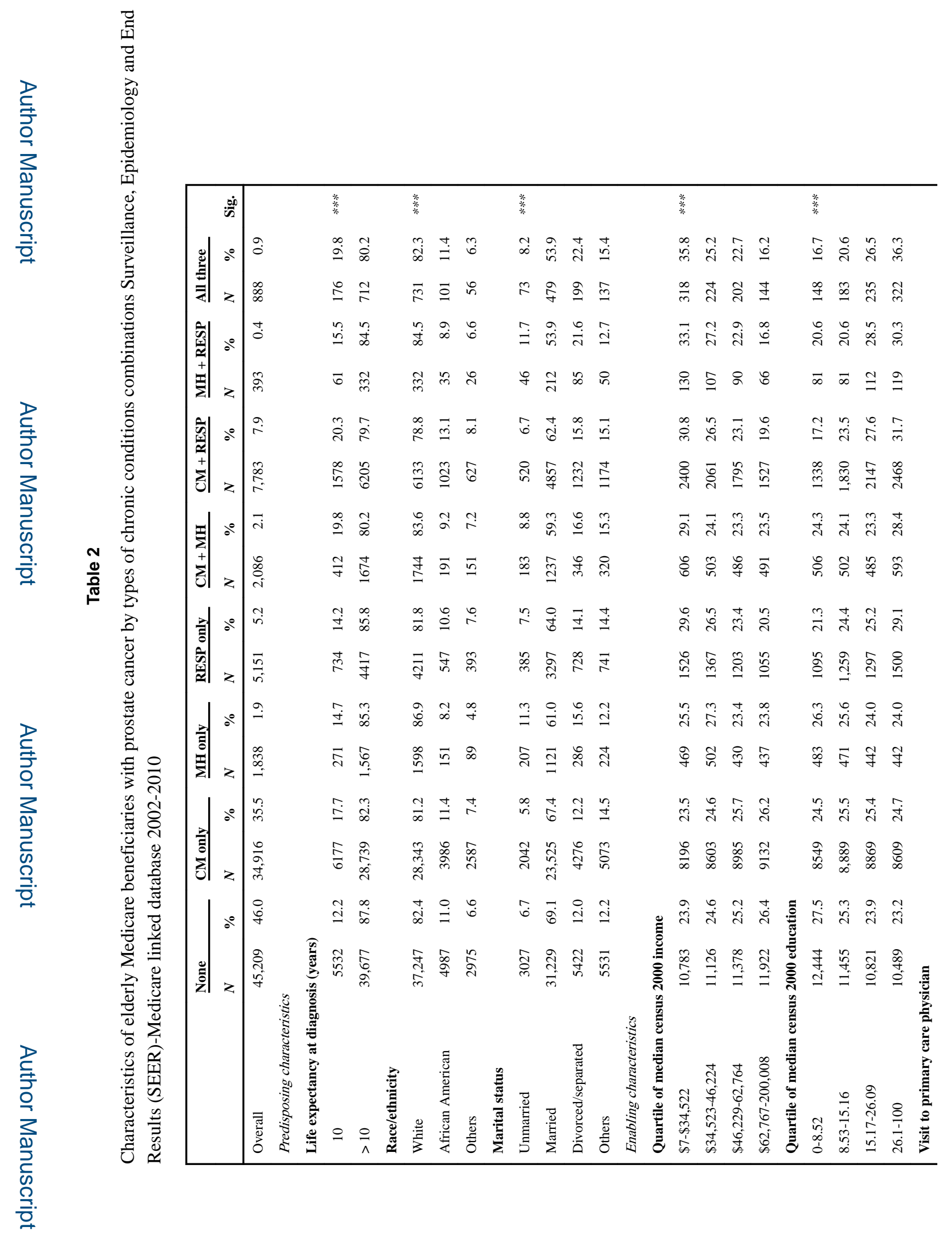

Int J Clin Pract. Author manuscript; available in PMC 2017 July 01. 


\begin{tabular}{|c|c|c|c|c|c|c|c|c|c|c|c|c|c|c|c|c|c|c|c|c|c|c|c|c|c|c|}
\hline & $\ddot{\Delta \overrightarrow{0}}$ & 冞 & & & 亚 & & & & & 䅈 & & & & & 桠 & & & 粰 & & & & * & & * & & 0 \\
\hline 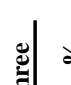 & $\therefore$ & & & & वे & $\overline{\mathrm{i}}$ & $\stackrel{\tilde{n}}{\underline{n}}$ & $\stackrel{m}{\mathrm{~m}}$ & & $\frac{\infty}{m}$ & Iे & तें & है & & 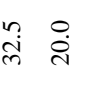 & $\stackrel{\infty}{\stackrel{0}{0}}$ & 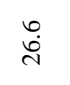 & $\frac{n}{n}$ & $\frac{4}{6}$ & & & & $\stackrel{\infty}{\sigma}$ & & $\stackrel{\tilde{q}}{q}$ & 愛 \\
\hline 馬 & $z$ & \& & I & & $\underset{\infty}{\infty}$ & d & $\stackrel{\sim}{\dddot{m}}$ & $\stackrel{n}{m}$ & & $\infty$ & $E$ & 孛 & તેป & & ه্ণ $\stackrel{\infty}{\subseteq}$ & $\stackrel{\infty}{\infty}$ & ల్ల & i & $\bar{q}$ & & & $\approx$ & $\frac{n}{\infty}$ & & $\sqrt{m}$ & 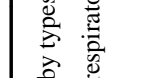 \\
\hline 氛 & $\therefore$ & $\underset{\infty}{\infty}$ & & & $\stackrel{\circ}{m}$ & $\stackrel{\infty}{\dot{m}}$ & $\stackrel{3}{2}$ & ले & & $\frac{m}{m}$ & $\hat{\mathrm{d}}$ & $\stackrel{0}{\stackrel{1}{0}}$ & & & 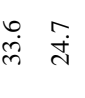 & $\stackrel{\infty}{\varrho}$ & $\overrightarrow{\vec{\lambda}}$ & हे & $\bar{c}$ & & & $\stackrel{\circ}{\varrho}$ & 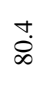 & 岾 & $\begin{array}{l}m \\
\xi \\
q\end{array}$ & 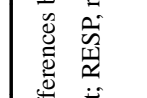 \\
\hline 弆 & $z$ & : & 8 & & in & $\cong$ & 8 & in & & $\tilde{I}$ & $\stackrel{2}{2}$ & $\vec{\infty}$ & 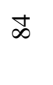 & & ฮิ & $\stackrel{\infty}{\triangleright}$ & $\triangleright$ & ¿ & $\overbrace{1}$ & & & 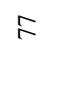 & $\stackrel{\circ}{m}$ & $\stackrel{n}{N}$ & $\stackrel{\infty}{\unlhd}$ & 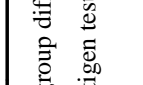 \\
\hline 氛 & 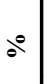 & $\underset{\substack{i \\
\infty}}{ }$ & $\stackrel{?}{=}$ & & $\stackrel{0}{2}$ & 杼 & $\stackrel{n}{2}$ & $\stackrel{\sim}{\infty}$ & & 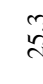 & तై & ત્ర & & & $\stackrel{m}{\vec{\sim}}=$ & 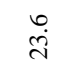 & $\stackrel{\circ}{\stackrel{d}{\sim}}$ & तี & $\begin{array}{ll}y \\
b \\
c\end{array}$ & & & 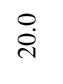 & $\stackrel{\circ}{\circ}$ & $\stackrel{\infty}{i}$ & $\stackrel{\widetilde{Z}}{\mathrm{~g}}$ & 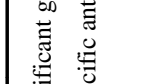 \\
\hline 竞: & z & 它 & $\stackrel{\infty}{\exists}$ & & हु & & 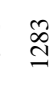 & ลे & & ลิ & હે & 旁 & 范 & & $\frac{n}{2} \stackrel{q}{d}$ & $\stackrel{+}{\stackrel{\infty}{\infty}}$ & $\stackrel{\hat{\lambda}}{\lambda}$ & $\frac{\mathcal{g}}{7}$ & $\begin{array}{ll}y \\
y \\
y \\
y\end{array}$ & & & $\begin{array}{l}\stackrel{\infty}{n} \\
\stackrel{n}{n}\end{array}$ & స్త్రి & 杀 & $\begin{array}{l}\hat{\mathrm{O}} \\
\stackrel{్}{2}\end{array}$ & 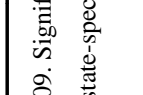 \\
\hline 国 & $\therefore$ & $\begin{array}{l}\text { ָे } \\
\infty \\
\infty\end{array}$ & & & ฉి & त्. & $\stackrel{\mathrm{I}}{ }$ & $\tilde{y}$ & & $\ddot{7}$ & $\stackrel{\circ}{\mathrm{d}}$ & तु & & & 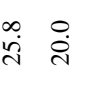 & 己ֶं & $\overrightarrow{\grave{\lambda}}$ & 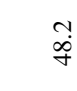 & $\begin{array}{ll}y & \alpha \\
\vdots & 9\end{array}$ & & & लें & $\overrightarrow{5}$ & & $\vec{j}$ & \\
\hline हो & z & f & సี & & ন & $\widetilde{g}$ & : & $\bar{\Xi}$ & & g) & 8 & $\tilde{n}$ & $i$ & & $\stackrel{\infty}{\stackrel{\infty}{n}} \frac{\infty}{\sigma}$ & $\stackrel{\infty}{i}$ & $\stackrel{\sim}{\infty}$ & 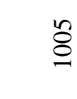 & $\underline{a}$ & & & $\hat{\infty}$ & बे & & $\stackrel{0}{\infty}$ & \\
\hline 常。 & $\therefore$ & $\stackrel{و}{\stackrel{2}{r}}$ & $\overline{\mathrm{i}}$ & & 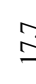 & 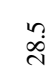 & $\stackrel{\text { I }}{=}$ & $\stackrel{\circ}{\vec{f}}$ & & กे & $\stackrel{\sim}{I}$ & $\vec{i}$ & तે & & $\overrightarrow{\bar{m}} \overline{\vec{\lambda}}$ & बे & $\widehat{\vec{\lambda}}$ & $\stackrel{+}{\stackrel{+}{n}}$ & $\begin{array}{ll}+ \\
f\end{array}$ & & & ले & $\bar{j}$ & $\stackrel{a}{i}$ & $\overrightarrow{\mathrm{j}}$ & \\
\hline 氛 & z & $\overline{\widetilde{Y}}$ & : & & $\frac{J}{a}$ & ơ & $\hat{g}$ & s & & $\stackrel{\infty}{\underbrace{2}}$ & $\stackrel{\text { S }}{\text { I }}$ & త్తి & $\stackrel{\varrho}{\Xi}$ & & $\stackrel{\underline{m}}{=}$ & త్తి & $\stackrel{\vec{\infty}}{=}$ & 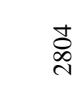 & 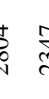 & & & $\stackrel{\vec{\infty}}{\stackrel{\infty}{\infty}}$ & \&్ల & $\begin{array}{l}\vec{\circ} \\
\stackrel{\sim}{े}\end{array}$ & $\stackrel{?}{\lambda}$ & $\begin{array}{l}\text { 吾 } \\
\text { 芯 }\end{array}$ \\
\hline & $\therefore$ & $\begin{array}{l}\infty \\
\stackrel{\infty}{\infty}\end{array}$ & & & $\stackrel{\infty}{=}$ & & $\stackrel{\infty}{\varrho}$ & $\ddot{z}$ & & $\frac{n}{2}$ & $\stackrel{+}{\stackrel{+}{d}}$ & 岇 & & & 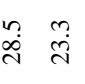 & 艾 & $\stackrel{\vec{\lambda}}{\dot{\lambda}}$ & $\vec{g}$ & 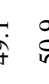 & & & $\ddot{\sim}$ & $\begin{array}{l}\infty \\
\dot{f} \\
\dot{q}\end{array}$ & $\overline{8}$ & ले & \\
\hline 芳 & $z$ & $\begin{array}{l}\infty \\
\stackrel{0}{0} \\
\stackrel{2}{n}\end{array}$ & స్ & & స్ & $m$ & $\stackrel{\infty}{=}$ & হे & & in & f & \& & $\bar{\Im}$ & & ત્ને & $\mathscr{8}$ & $\tilde{y}$ & ઠे & d & & & 命 & $\vec{\triangleright}$ & $\stackrel{t}{\stackrel{\Xi}{=}}$ & 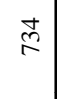 & \\
\hline 8 & $\Delta^{\circ}$ & $\begin{array}{l}0 \\
\stackrel{0}{\circ}\end{array}$ & $\stackrel{\vec{i}}{\dot{i}}$ & & 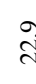 & $\ddot{\pi}$ & $\stackrel{\sim}{\sim}$ & $\hat{q}$ & & & $\stackrel{0}{\stackrel{0}{+}}$ & $\stackrel{m}{i}$ & $\begin{array}{l}0 \\
\dot{a} \\
\dot{a}\end{array}$ & & $\begin{array}{ll}n \\
\stackrel{\sim}{*} & 0 \\
\end{array}$ & $\stackrel{\circ}{\stackrel{\lambda}{\lambda}}$ & $\begin{array}{l}\infty \\
\stackrel{d}{i}\end{array}$ & กั & $y_{0}^{1}$ & & & $\stackrel{m}{i}$ & 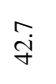 & $\ddot{n}$ & $\hat{\dot{q}}$ & \\
\hline 章 & $z$ & & $\underset{\infty}{\stackrel{\infty}{\triangleright}}$ & & 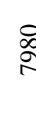 & $\frac{\wp}{\infty}$ & 嗃 & 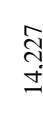 & & & {$\left[\begin{array}{l}\tilde{n} \\
\text { in } \\
\infty\end{array}\right.$} & 芴 & 芯 & & 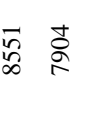 & $\bar{g}$ & శ్రి & $\stackrel{\vec{n}}{s}$ & $E$ & & & $\begin{array}{l}0 \\
\stackrel{0}{0} \\
\stackrel{i}{0}\end{array}$ & $\begin{array}{l}\stackrel{8}{\circ} \\
\text { తे }\end{array}$ & ᄅे & $\begin{array}{l}\stackrel{n}{c} \\
\stackrel{v}{ \pm} \\
-\end{array}$ & 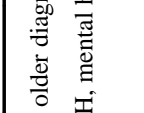 \\
\hline$\theta$ & $\therefore$ & $\stackrel{\circ}{i}$ & $\stackrel{\circ}{\stackrel{m}{m}}$ & & & $\stackrel{\text { İ }}{\text { d }}$ & $\stackrel{\overbrace{}}{=}$ & : & & & $\stackrel{\infty}{+}$ & 곡 & $\stackrel{\circ}{\stackrel{+}{\sim}}$ & & $\begin{array}{cc}\vec{\sim} & n \\
\overrightarrow{\mathrm{N}}\end{array}$ & సֶ. & $\stackrel{\text { If }}{\mathrm{J}}$ & $\begin{array}{l}\text { ¿ } \\
\text { in }\end{array}$ & i & + & & $\stackrel{t}{\stackrel{f}{\circ}}$ & 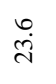 & $\begin{array}{l}0 \\
\dot{\infty} \\
i\end{array}$ & $\stackrel{\vec{\sigma}}{\vec{\sigma}}$ & \\
\hline & $z$ & $\stackrel{\infty}{=}$ & 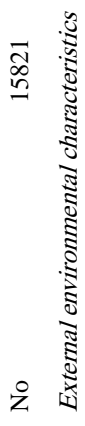 & 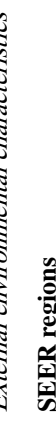 & $\widehat{\Sigma}$ & & 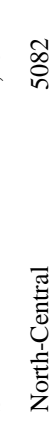 & 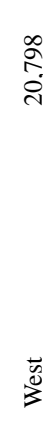 & 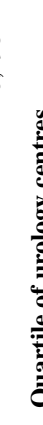 & & $\stackrel{\widetilde{N}}{=}$ & $\frac{ \pm}{I}$ & $\begin{array}{l} \\
\\
q \\
f \\
f \\
y \\
y\end{array}$ & 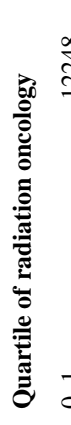 & 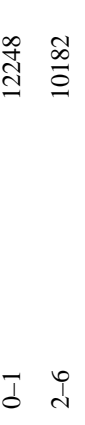 & $\frac{1}{3}$ & 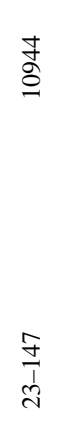 & 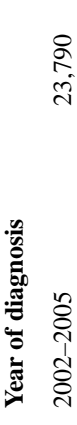 & 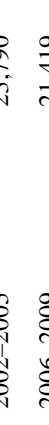 & & 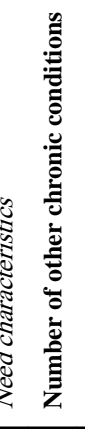 & 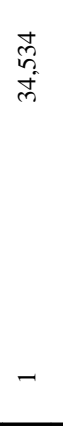 & $\begin{array}{l}n \\
6 \\
0 \\
0\end{array}$ & 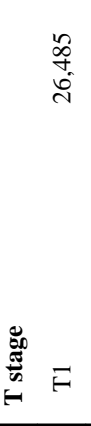 & $\underset{N}{\stackrel{N}{N}}$ & 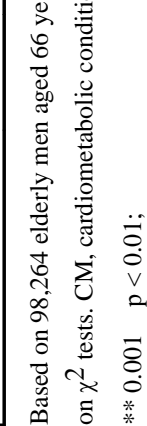 \\
\hline
\end{tabular}

Int J Clin Pract. Author manuscript; available in PMC 2017 July 01. 

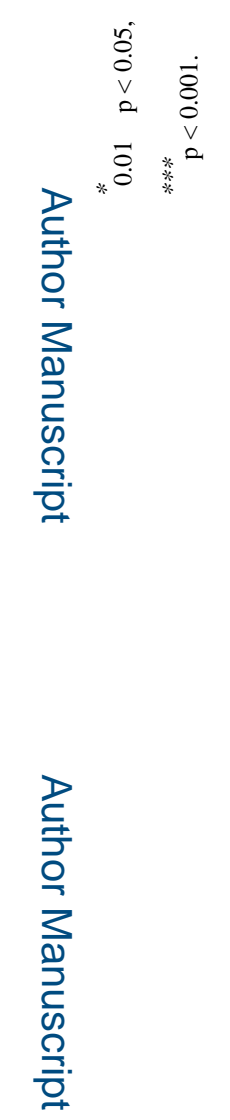

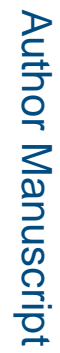

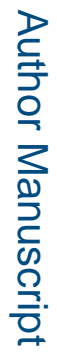

Int J Clin Pract. Author manuscript; available in PMC 2017 July 01. 


\section{Table 3}

Number and percentage with initial cancer treatment by types of chronic conditions combinations unadjusted and adjusted odds ratios and 95\% confidence intervals from multinomial logistic regressions among elderly Medicare beneficiaries with prostate cancer Surveillance, Epidemiology and End Results (SEER)-Medicare linked database 2002-2010

\begin{tabular}{|c|c|c|c|c|c|c|c|c|c|}
\hline & \multicolumn{2}{|l|}{$\underline{\mathbf{R P}}$} & \multicolumn{2}{|l|}{$\underline{\text { RT }}$} & \multicolumn{2}{|c|}{ Hormone therapy } & \multicolumn{2}{|l|}{ None } & \multirow[b]{2}{*}{ Sig. } \\
\hline & $N$ & $\%$ & $N$ & $\%$ & $N$ & $\%$ & $N$ & $\%$ & \\
\hline All & 21,745 & 22.1 & 46,617 & 47.4 & 10,272 & 10.5 & 19,630 & 20.0 & \\
\hline \multicolumn{10}{|c|}{ Types of chronic conditions combinations } \\
\hline None & 11,064 & 24.5 & 21,106 & 46.7 & 3830 & 8.5 & 9209 & 20.4 & $* * *$ \\
\hline CM only & 6941 & 19.9 & 17,288 & 49.5 & 3985 & 11.4 & 6702 & 19.2 & \\
\hline MH only & 451 & 24.5 & 779 & 42.4 & 194 & 10.6 & 414 & 22.5 & \\
\hline RESP only & 1151 & 22.3 & 2,451 & 47.6 & 595 & 11.6 & 954 & 18.5 & \\
\hline $\mathrm{CM}+\mathrm{MH}$ & 469 & 22.5 & 869 & 41.7 & 294 & 14.1 & 454 & 21.8 & \\
\hline $\mathrm{CM}+\mathrm{RESP}$ & 1390 & 17.9 & 3609 & 46.4 & 1188 & 15.3 & 1596 & 20.5 & \\
\hline $\mathrm{MH}+\mathrm{RESP}$ & 87 & 22.1 & 177 & 45.0 & 47 & 12.0 & 82 & 20.9 & \\
\hline All three & 192 & 21.6 & 338 & 38.1 & 139 & 15.7 & 219 & 24.7 & \\
\hline \multicolumn{10}{|c|}{ Adjusted model - initial cancer treatment $(\operatorname{Ref}=$ no treatment $)$} \\
\hline & \multicolumn{3}{|l|}{$\underline{\mathbf{R P}}$} & \multicolumn{3}{|l|}{$\underline{\text { RT }}$} & \multicolumn{3}{|c|}{ Hormone therapy } \\
\hline & AOR & $95 \% \mathrm{CI}$ & Sig. & AOR & $95 \% \mathrm{CI}$ & Sig. & AOR & $95 \% \mathrm{CI}$ & Sig. \\
\hline \multicolumn{10}{|c|}{ Types of chronic conditions combinations } \\
\hline None & 1.31 & $1.06-1.62$ & * & 1.48 & $1.24-1.77$ & $* * *$ & 0.89 & $0.71-1.11$ & \\
\hline CM only & 1.17 & $0.95-1.44$ & & 1.61 & $1.35-1.93$ & $* * *$ & 1.04 & $0.83-1.30$ & \\
\hline MH only & 1.07 & $0.83-1.37$ & & 1.13 & $0.91-1.40$ & & 0.87 & $0.66-1.16$ & \\
\hline RESP only & 1.30 & $1.04-1.62$ & $*$ & 1.61 & $1.33-1.96$ & $* * *$ & 1.03 & $0.81-1.32$ & \\
\hline $\mathrm{CM}+\mathrm{MH}$ & 1.17 & $0.91-1.49$ & & 1.26 & $1.02-1.56$ & * & 1.10 & $0.84-1.44$ & \\
\hline $\mathrm{CM}+\mathrm{RESP}$ & 1.03 & $0.83-1.28$ & & 1.47 & $1.22-1.77$ & $* * *$ & 1.13 & $0.89-1.42$ & \\
\hline $\mathrm{MH}+\mathrm{RESP}$ & 1.07 & $0.74-1.57$ & & 1.34 & $0.97-1.85$ & & 0.91 & $0.59-1.40$ & \\
\hline All three & Ref & & & Ref & & & & & \\
\hline
\end{tabular}

CM, cardiometabolic conditions; $\mathrm{MH}$, mental health conditions; Ref, reference group; RESP, respiratory conditions; Sig, level of significance. $* * 0.001 \leq \mathrm{p}<0.01$,

Based on 98,264 elderly men aged 66 years and older diagnosed with prostate cancer between 2002 and 2009. Significant differences in initial cancer treatment by types of chronic conditions combinations were based on $\chi^{2}$ test. Significant differences by types of chronic conditions combinations were based on the log-likelihood test using a logistic regression for adjusted model. Adjusted model controlled for predisposing (life expectancy, race/ ethnicity, marital status), enabling (income, education, access-care, cancer screening), need (number of other chronic conditions, cancer stage) and external environmental factors (county level radiation unit, urology units, regions, year of diagnosis). * $0.01 \leq \mathrm{p}<0.05$, **** $\mathrm{p}<0.001$. 


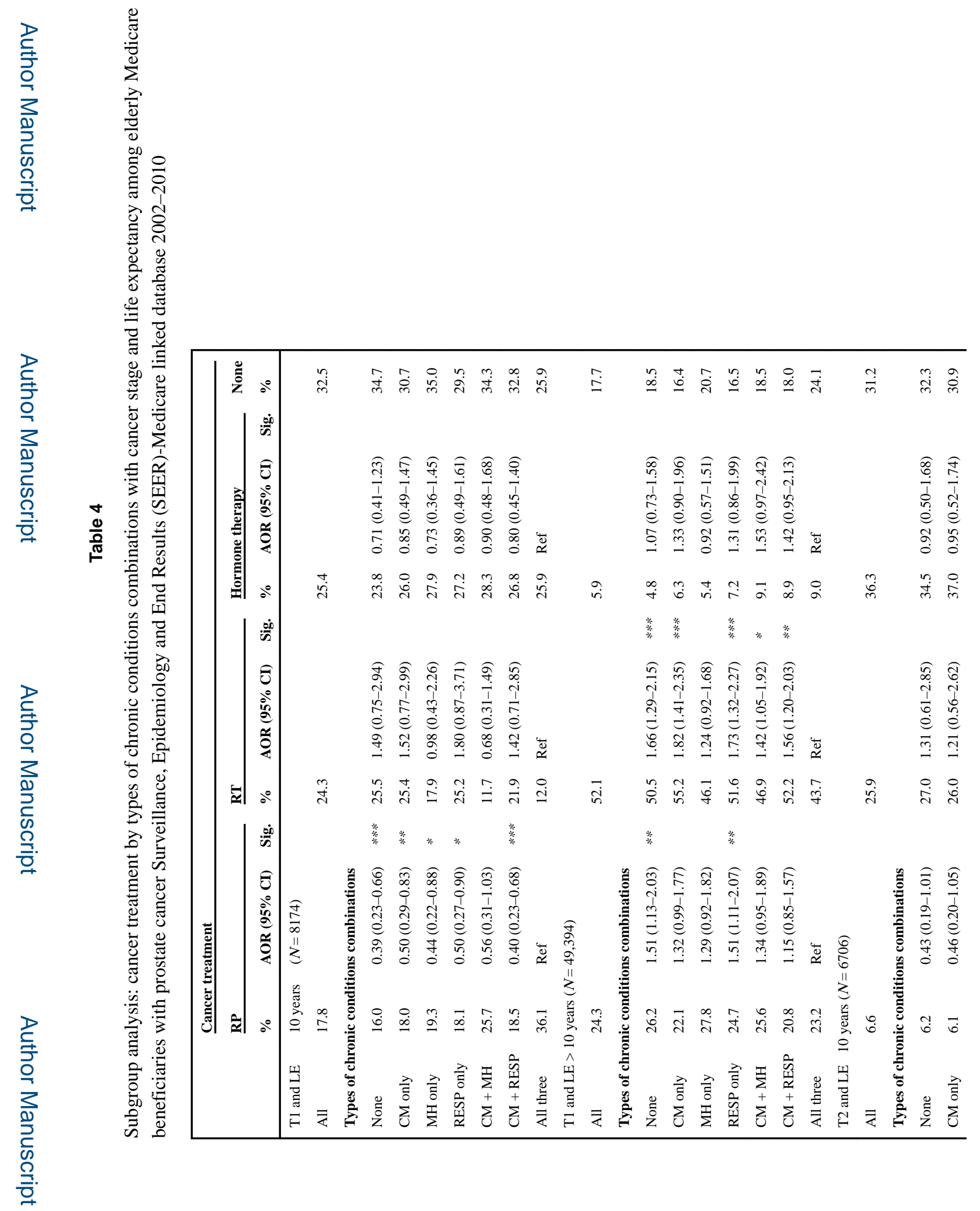

Int J Clin Pract. Author manuscript; available in PMC 2017 July 01. 
$\overline{8}$

: : 会 हैं + 产密

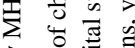

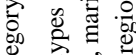

क्ष

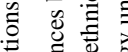

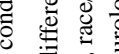

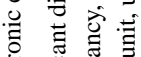

常。

is

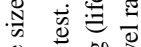

8

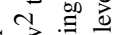

结

을

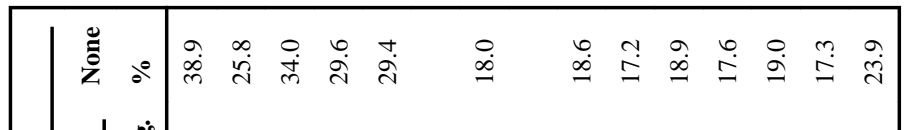

范

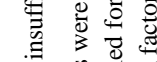

क⿺辶)

क्ष

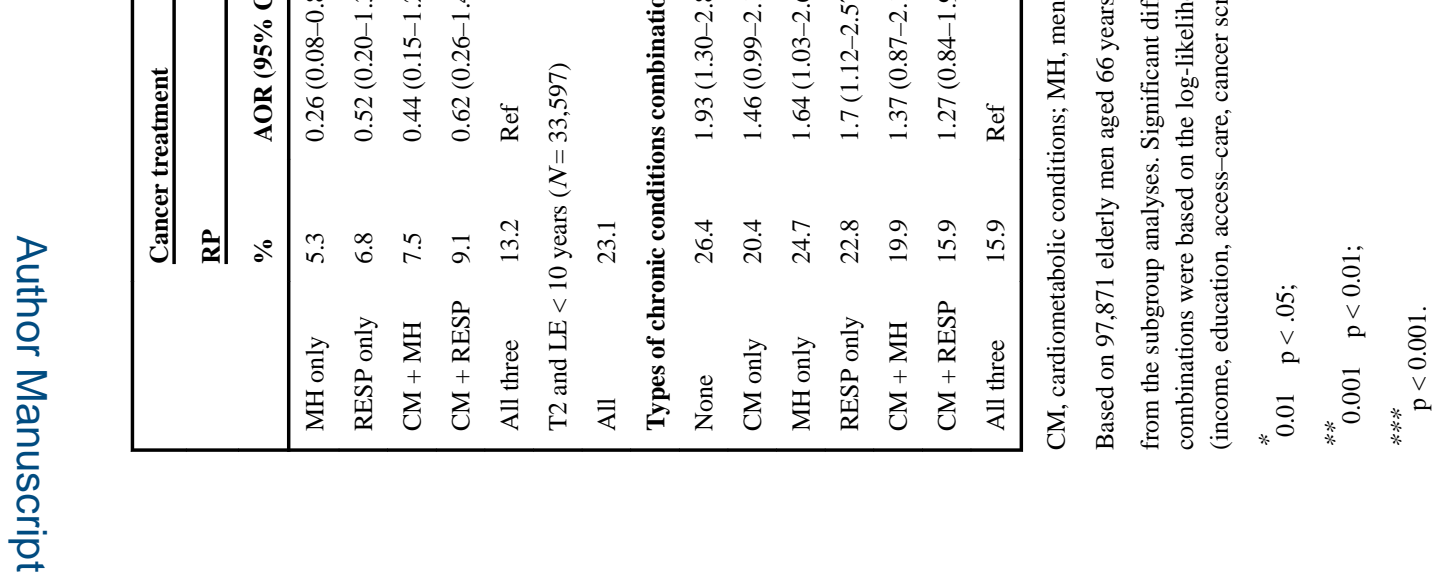

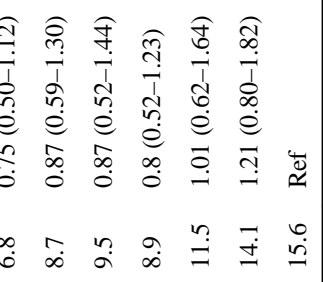

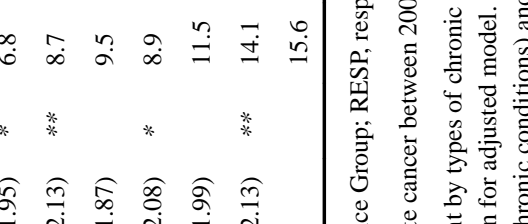

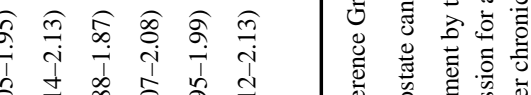



¿ e $\doteq$ e

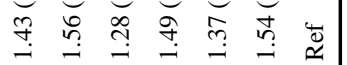

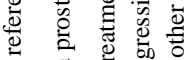

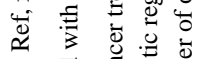

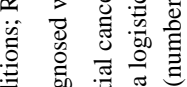

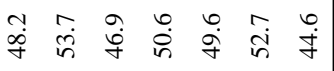

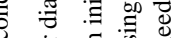

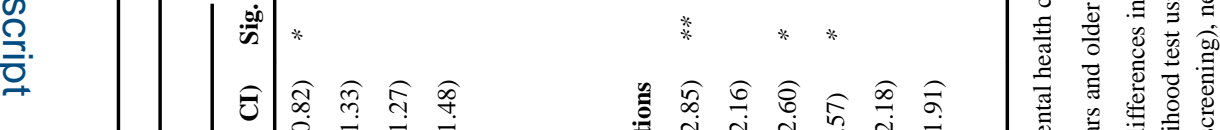

Int J Clin Pract. Author manuscript; available in PMC 2017 July 01. 


\section{Appendix 1}

Codes to identify radiation therapy, surgery, hormonal and chemotherapy utilisation among elderly Medicare beneficiaries with prostate cancer using Surveillance, Epidemiology and End Results-Medicare linked data 2002-2010

\begin{tabular}{|c|c|c|c|c|c|c|}
\hline \multirow[b]{2}{*}{ Types of therapy } & \multicolumn{3}{|l|}{ Medicare claims } & \multicolumn{3}{|l|}{ SEER } \\
\hline & $\begin{array}{l}\text { ICD-9 } \\
\text { procedure } \\
\text { codes in } \\
\text { MedPAR/SAF }\end{array}$ & $\begin{array}{l}\text { ICD-9 } \\
\text { diagnostic } \\
\text { codes in } \\
\text { MedPAR/SAF }\end{array}$ & $\begin{array}{l}\text { CPT- } 4 \text { codes in } \\
\text { NCH/Carrier file/SAF }\end{array}$ & $\begin{array}{l}\text { Surgery } \\
\text { codes }\end{array}$ & $\begin{array}{l}\text { Radiation } \\
\text { codes }\end{array}$ & $\begin{array}{l}\text { Revenue centre } \\
\text { codes }\end{array}$ \\
\hline \multicolumn{7}{|l|}{ Active treatment } \\
\hline Radical prostatectomy & $60.2-60.6$ & & $\begin{array}{l}55810,55812,55840,55842, \\
55845,55815,55866\end{array}$ & $30,50,80$ & & \\
\hline Radiation therapy & $\begin{array}{l}9221-9229 \\
9227,4604 \\
4610\end{array}$ & $\begin{array}{l}\text { V58.0, V66.1, } \\
\text { V67.1 }\end{array}$ & $\begin{array}{l}55859,55860,55862,55865, \\
55875,7687376968, \\
77261-77299,77300,77301 \\
77305,77326,77327, \\
77328,77338,77401-77499, \\
77520,77522,77523, \\
77525,77750-77799, \mathrm{C} 1164, \\
\text { C1174, C1325, C1350 } \\
\text { C1700-C1712, C1715-C1720, } \\
\text { C1728 C1790-C1806, } \\
\text { C2638 C2639, C2640 C2641, } \\
\text { G0256, G0261, Q3001, } \\
0073 T\end{array}$ & & $1-5,7$ & 0330 or 0333 \\
\hline Hormonal therapy & 62.4 & & $\begin{array}{l}\text { J1950, J9217-J9219, J9202, } \\
\text { J9165, 54520, 54521, } \\
54522,54530,54535\end{array}$ & 01 & & \\
\hline
\end{tabular}

3D-CRT, three-dimensional conformal radiation therapy; MIRP, minimum invasive robotic radical prostatectomy; CPT-4, current procedural terminology, fourth edition; ICD-9, International Classification of Diseases, ninth revision; IMRT, intensity-modulated radiation therapy; LRP, laparoscopic radical prostatectomy; Open RP, open radical prostatectomy. 


\section{Appendix 2}

Codes used to identify the types of chronic conditions and list of other chronic conditions among elderly Medicare beneficiaries with incident prostate cancer Surveillance, Epidemiology, and End Results-Medicare linked data of 2002-2009

\begin{tabular}{|c|c|}
\hline Types of chronic conditions & ICD-9 diagnostic codes \\
\hline \multicolumn{2}{|l|}{ Cardiometabolic conditions } \\
\hline Coronary artery disease & $410,411,412,413,414$ \\
\hline Congestive heart failure & $402.01,402.11,402.91,404.01,404.11,404.91,428$ \\
\hline Conductive disorders & $423,427.31$ \\
\hline Diabetes & 250 \\
\hline \multicolumn{2}{|l|}{ Mental health conditions } \\
\hline Depression & $296.2,296.3,311,300.4,311,300.4$ \\
\hline Bipolar disorders & 296.0, 296.1, 296.4, 296.5, 296.6,296.7, 296.8, 296.9 \\
\hline Schizophrenia & 297, 298, 299 \\
\hline Psychoses & 309.81 \\
\hline Anxiety & $300.0,300.2,300.3$ \\
\hline \multicolumn{2}{|l|}{ Respiratory conditions } \\
\hline COPD and other pulmonary conditions & $490,491,492,495,496,500,501,502,503,504,505,506.4$ \\
\hline Asthma & 493 \\
\hline \multicolumn{2}{|l|}{ List of other chronic conditions } \\
\hline \multicolumn{2}{|c|}{$\begin{array}{l}\text { Abuse of drugs, acute renal failure, AIDS, alcohol abuse, amputations, blindness, cerebrovascular disease, chronic renal failure, cognitiv } \\
\text { impairment, dementia, } \\
\text { diverticulitis, end-stage kidney disease, end-stage liver disease, epilepsy, gallstones, gangrene, gastritis, gastroparesis, GERD, gout, } \\
\text { hemiplegia, hip arthoplasty, low } \\
\text { back pain, multiple sclerosis, muscular dystrophy, nephropathy, nephrotic syndrome, osteoarthritis, Parkinson's disease, peptic ulcers, } \\
\text { peripheral vascular disease, } \\
\text { retinopathy, rheumatoid arthritis, spinal cord injury, systemic lupus erythematous, ulcer, viral hepatitis }\end{array}$} \\
\hline
\end{tabular}

Int J Clin Pract. Author manuscript; available in PMC 2017 July 01. 